[ FAUSTO VIANA | ROSANE MUNIZ ]

Fausto Viana e Rosane Muniz são pesquisadores, figurinistas e professores. Ele, na ECA-USP; ela, na Escola de Belas Artes de São Paulo. Têm livros de autoria própria: O figurino teatral e as renovações do século XXé dele, e Vestindo os nus: o figurino em cena, dela. Juntos, já fizeram inúmeros artigos e textos, e organizaram as publicações Diário das escolas: cenografia e Diário de pesquisadores: traje de cena. E-mails: faustoviana@uol.com.br | romuniz@gmail.com

\title{
Traje de cena: um negócio na (da) China
}

Não é de hoje que o teatro do Ocidente busca inspiração no teatro oriental. Da Índia, vieram as fortes apresentações de Kathakali e outras formas antigas de teatro e dança. Isso sem contar a febre dos filmes de Bollywood, que inspiraram obras como 0 filme Moulin Rouge (2001). Do Japão, os conhecidos e respeitados teatros Nô, Kabuki, Kyogen e o teatro de bonecos Bunraku, além de outras tendências mais contemporâneas, como o Butô, do qual Kazuo Ohno é o representante máximo. Do cinema japonês, é impossível não citar Akira Kurosawa (1910-1998) e obras dirigidas por ele, como Rashomon (1950), Os Sete Samurais (1954), Sonhos (1990) e Madadayo (1993).

Da China, sempre tivemos a impressionante estética da Ópera de Pequim, com seus mais de trezentos anos de tradição. Mais uma vez, foi o cinema que a popularizou por aqui, com o filme Minha Adorável Concubina (1993), dirigido por Chen Kaige.

[36] Também temos 0 Último Imperador, de Bernardo Bertolucci, sobre a vida do último imperador da China Imperial, ganhador do Oscar de melhor filme em 1988, além de mais oito estatuetas em diversas categorias, incluindo, claro, melhor figurino. Todos esses fazem parte da série de filmes que precisam ser vistos. Se ainda não assistiu, corra e veja hoje, não importa o que aconteça!

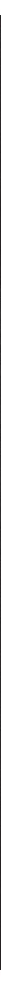

Foto de cena de O Último Imperador, de Bernardo Bertolucci (1988). 
Pesquisadores do teatro ocidental das mais remotas épocas, como os russos Stanislavski (1863-1938) e Meyerhold (1874-1940), os ingleses Edward Gordon Craig (1872-1966) e Peter Brook (1925), os franceses Antonin Artaud (1896-1948) e Ariane Mnouchkine (1939), o alemão Bertolt Brecht (1898-1956) e uma miriade de outros artistas pesquisadores já confessaram abertamente sua admiração pelo estilo e pelas técnicas orientais.

Nas performances, nos espetáculos convencionais, no teatro comercial - enfim, em muitas formas do fazer teatral -, a presença do teatro oriental é marcante. Nós nos dispusemos a investigar na China, em 2013, como o teatro oriental vê o ocidental. Fomos até a Shanghai Theater Academy, uma escola fundada em 1945 e que tem hoje 2.400 alunos distribuídos em três campi. Os cursos são de direção, interpretação, literatura dramática, cenografia, TV, ópera tradicional e dança contemporânea e tradicional.

Nossa entrevistada principal foi a professora Xu Jiahua, chefe do Departamento de Traje de Cena, além de Fan Congbo, Quan Jin e Wu Xian, também professoras.

Xu Jiahua é muito respeitada por todas, o que fica evidente pelo comportamento das outras durante a entrevista, ou mesmo quando elas falam de sua importância. Jiahua trabalhou muito pelo teatro chinês e realizou uma grande quantidade de desenhos de figurinos e maquiagem. Formou-se na mesma escola em que dá aulas, e fica claro que seu cartão de visitas atual é a abertura das Olimpíadas de 2008, em Pequim. Responsável pelos trajes e pela maquiagem, em busca da beleza oriental, coordenou uma equipe de 700 maquiadores para trabalhar com os 15.000 figurantes da abertura.

Jiahua trabalha muito com a maquiagem tradicional por achar importante que os alunos tenham contato com esse tipo de tradição, afinal, é um trabalho de base para outras coisas.

Ela contou que muitos textos considerados clássicos do teatro inglês, russo e americano foram traduzidos e incorporados ao teatro chinês já a partir de 1983. E revelou que essas produções foram gradativamente influenciando o modo local de criação de trajes de cena. Naturalmente, a ópera chinesa sempre fez parte do repertório.

Mas muitas coisas mudaram no fazer teatral da China. "Hoje", afirma Jiahua, "temos uma diversidade maior de autores que não são famosos no mundo todo. É o caso de óperas experimentais e peças mais irregulares". As inovações vêm de encontro ao desejo pessoal da figurinista, que se diz muito cansada de fazer teatro tradicional e expressou o desejo de se dedicar agora mais aos projetos experimentais. Mas a jornada não é fácil. "Os diretores da escola são sempre muito conservadores", é o que ela afirma, em tom crítico e de mulher inquieta. "Nós queremos criar nós mesmas. Há alguns anos, um diretor disse: figurinos não são necessários, maquiagem não é necessária. Ele dizia que jogar um pedaço de pano nas costas já resolvia o problema".

Percebemos o que ela deseja é liberdade criativa, inclusive para recriar a tradicional ópera chinesa!




Quando perguntamos se achava que o teatro chinês havia sido influenciado por alguma forma de teatro ocidental, Jiahua esclareceu que o gênero operístico do ocidente sempre esteve presente. Mas que, nesses últimos cinco anos, o que mais tinha influenciado os trajes chineses foram os musicais americanos, como $O$ Rei Leão.

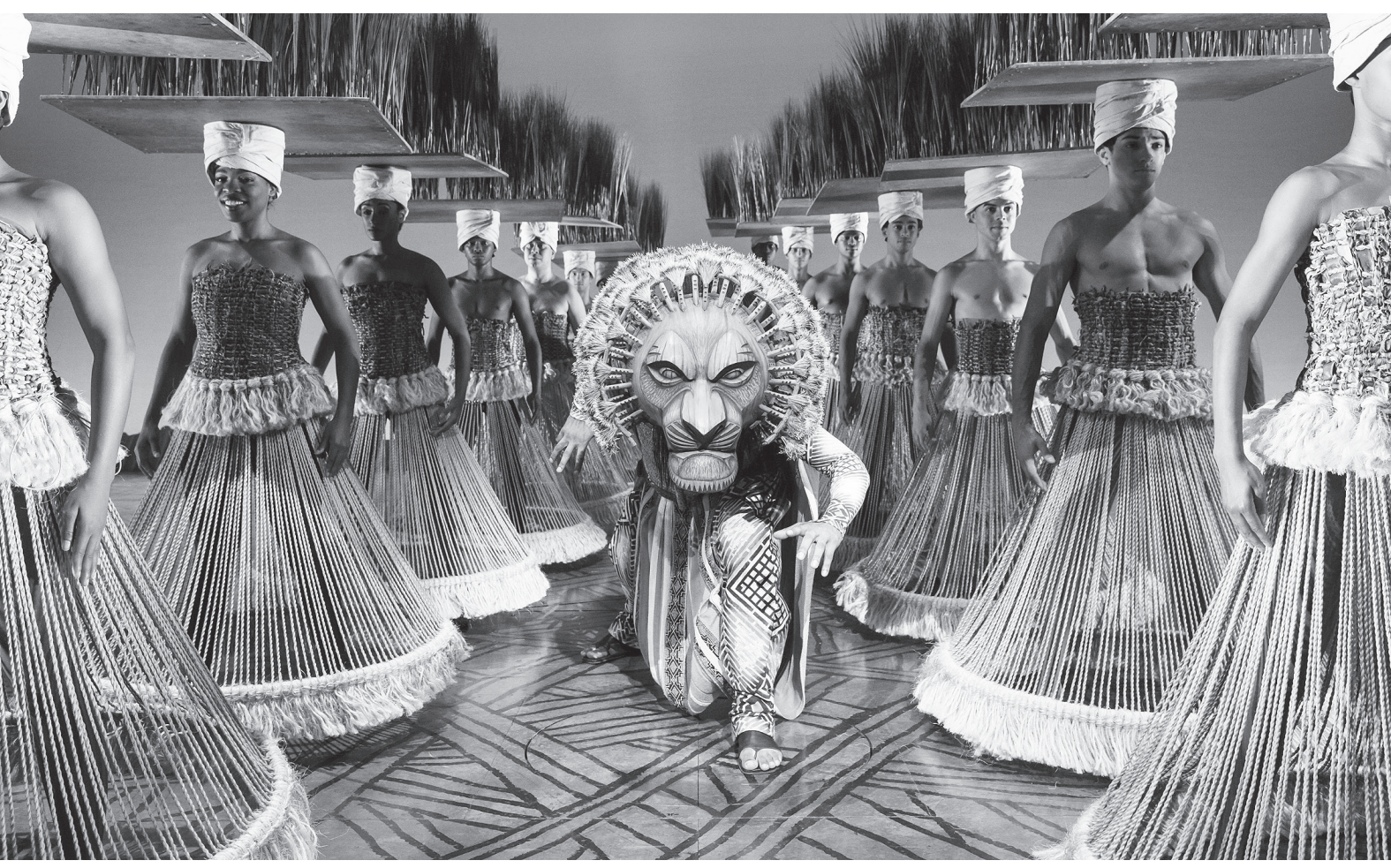

Será que depois de tantos anos admirando a tradição do teatro chinês vamos finalmente ver na China os mesmos figurinos pasteurizados que temos visto em muitas ocasiões hoje em dia por todo o mundo? Mais uma vez, quem era diferente deixa a sua cultura original de lado para entrar em um esquema geral e seguir os mesmos padrões de produção?

Segundo Jiahua: "Nada será igual, um país não poderá ser igual ao outro. Cada um tem sua cultura, seu estilo próprio. Cada um tem suas próprias ideias". Fan Congbo, professora da mesma universidade, afirma: "Penso da mesma forma que a professora. Podemos aprender uns com os outros, cada país aprende com o outro", e comenta que, no entanto, espera que aconteçam mais conexões entre as pessoas.

Quan Jin, professora de figurino, lembra que como a tecnologia tem força muito grande nos palcos chineses de hoje, ela mesma vai gerar materiais novos a serem empregados nos trajes. "A partir da base tradicional, a tecnologia trará muitas mudanças. E isso inclui uma mudança visual e dos temas a serem abordados no palco", esclarece a jovem.

Wu Xian, sua colega de trabalho, acrescenta que a tecnologia vai mesmo trazer muitas novidades, inclusive no que se refere ao material de maquiagem. Mas, para ela, tecnologia não é tudo. Ela fala - e é quase aplaudida por todos os presentes na entrevista - que as relações humanas têm que estar mais presentes. Deve haver humanidade nas relações. A professora Jin complementou que "pessoas com formações culturais diferentes terão atitudes diferentes. Será como montar Shakespeare. Você usa a sua cultura, e eu, a minha; cada país tem a sua cultura".

A esperança no pensamento humano ficou presente. Quando abrimos para a participação dos alunos, uma delas disse brilhantemente que "o pensamento criativo é o mais importante! É uma forma de atualizar sempre o seu pensamento, as suas ideias".

A China, mais uma vez, se reinventa. "0 que é que vai sair daí?", é o que podemos nos perguntar nos próximos anos, pois a China - um dos tigres asiáticos - é hoje a segunda maior potência financeira do mundo.

E nós sabemos bem o que o poderio financeiro faz nas artes... 